\title{
Relationship between symptoms of attention-deficit/hyperactivity disorder and speech-language-hearing aspects
}

Nárli Machado-Nascimento'

https://orcid.org/0000-0002-7600-3887

Arthur Melo e Kümmer ${ }^{2}$ https://orcid.org/0000-0003-3941-0931

Stela Maris Aguiar Lemos ${ }^{3}$ https://orcid.org/0000-0003-4104-5179

Universidade Federal de Minas Gerais UFMG, Programa de Pós-Graduação em Neurociências, Belo Horizonte, Minas Gerais, Brasil

2 Grupo EMS Sigma Pharma - Pesquisa Clínica, Hortolândia, São Paulo, Brasil

3 Universidade Federal de Minas Gerais - UFMG, Faculdade de Medicina, Departamento de Fonoaudiologia, Belo Horizonte, Minas Gerais, Brasil

This study was carried out in the SpeechLanguage-Hearing Sciences Postgraduate Program at the Universidade Federal de Minas Gerais - UFMG, Belo Horizonte, Minas Gerais, Brazil.

Source of support: Fundação de Amparo à Pesquisa do Estado de Minas Gerais FAPEMIG, Universal Announcement/2016, Process: APQ-03742-16; Coordenação de Aperfeiçoamento de Pessoal de Nivel Superior - CAPES, Finance Code 001.

Conflict of interests: Nonexistent

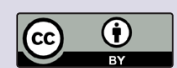

Received on: October 14, 2020 Accepted on: April 7, 2021

Corresponding address:

Nárli Machado-Nascimento

Avenida José Lopes Muradas, 80

CEP: 31.742-084 - Belo Horizonte

Minas Gerais, Brasil

E-mail: narli.m@gmail.com

\section{ABSTRACT}

Purpose: to investigate the association of symptoms of inattention and hyperactivity with language development and cognitive, environmental, socioeconomic, and quality of life aspects in children with attention-deficit/hyperactivity disorder.

Methods: an observational, analytical, cross-sectional study with a sex-stratified sample of 38 children 7 to 12 years old, diagnosed with attention-deficit/hyperactivity disorder. The assessments approached sociodemographic and environmental aspects, the quality of life, language comprehension, rapid automatic naming, phonological working memory, vocabulary, reading and writing processes and metalinguistic skills. Descriptive and bivariate analyses were conducted at the $5 \%$ significance level.

Results: there was a statistically significant association between the profile of attention-deficit/hyperactivity disorder and behavioral aspects. There was no significant association of the forms of manifestation of attention-deficit/hyperactivity disorder with the quality of life, oral language, written language and phonological processing skills.

Conclusion: children with hyperactive profiles had a better performance, whereas children with combined and predominantly inattentive profiles had similar performances. Although no statistically significant associations were found between attention-deficit/ hyperactivity disorder and most of the variables analyzed in this research, it contributes to the discussion of the speech-language-hearing diagnosis.

Keywords: Speech, Language and Hearing Sciences; Attention Deficit Hyperactivity Disorder; Language; Family; Quality of Life 


\section{INTRODUCTION}

The main symptoms of attention-deficit/hyperactivity disorder (ADHD) are inattention and hyperactivity/ impulsivity". The behavior manifested by a child or adolescent with ADHD is related to these symptoms and specific behaviors that impair different areas of their lives ${ }^{2}$. There is also a high incidence of symptoms of anxiety and depression ${ }^{3}$, not only in the children and adolescents with ADHD but in their relatives as well. In cases with comorbidities, the impact on the family's quality of life is even greater ${ }^{5}$. Hence, the relationship between ADHD symptomatology and quality of life aspects must be investigated.

The main comorbidities in ADHD include learning disorders, disruptive disorders, mood and anxiety disorders, conduct disorder, and oppositional defiant disorder ${ }^{6}$. The presence of these and other comorbidities is a hindering factor for the diagnosis of ADHD because the origin or cause of the child's or adolescent's difficulties is unknown.

Inattention manifests in ADHD as a lack of persistence, distraction from tasks, difficulty keeping focused, and disorganization. Hyperactivity, in its turn, is an excessive motor activity at inappropriate moments, whereas in impulsivity, there are hasty, thoughtless actions with a high potential of damage to the person ${ }^{1}$. These manifestations may be associated with speechlanguage-hearing changes, causing a great impact on the overall performance of children with ADHD. Various studies have revealed that children with ADHD have a lower performance in cognitive-linguistic tasks than children without the disorder-12. Other studies have investigated the quality of life $^{13}$ and resources in the family environment ${ }^{14}$ in cases of ADHD.

From the perspective of speech-language-hearing assistance to the ADHD patient, the changes related to the disorder or comorbidities must be investigated. To this end, the instruments used must characterize the symptomatology of the disorder and measure the impact of the symptoms on the children's quality of life. In this sense, the MTA-SNAP scale ${ }^{15}$ combined with language assessments in this study enables the triangulation between speech-language-hearing manifestations and ADHD symptoms.

The literature describes changes in reading ${ }^{7,8,10-12}$, metalanguage $^{8,12}$, and phonological processing ${ }^{9,10}$ in children and adolescents with ADHD. There is, though, a gap in terms of assessing all these elements in a single sample. Thus, such analyzed data can provide a more in-depth understanding of this population's speech-language-hearing profile.

The aim of this study was to investigate the association of symptoms of inattention and hyperactivity with language development and cognitive, environmental, socioeconomic, and quality of life aspects in children presented with ADHD.

\section{METHODS}

This study was approved by the Research Ethics Committee at the Universidade Federal de Minas Gerais (Federal University of Minas Gerais), Brazil, under evaluation report number 431.686. The children's parents/guardians signed the informed consent form upon agreeing with their participation in the research.

This is an observational, analytical, cross-sectional study with a sex-stratified non-probabilistic sample of 7- to 12-year-old children with ADHD.

This study comprised 7- to 12-year-old children diagnosed with ADHD referred by the Child Psychiatry, Neurology, or Pediatric Outpatient Centers of the Clinics Hospital at the Universidade Federal de Minas Gerais.

The sample size was calculated according to the variables of interest to this study, considering a simple random sample stratified by sex. Based on a $15 \%$ sample error and a $5 \%$ significance level, the sample would need to have at least 35 people -28 males and 7 females. The sample was constructed considering 57 children referred for assessment at the SpeechLanguage-Hearing Outpatient Center. The children eligible for the study were identified from this outpatient center's appointment schedule and selected after confirming in the medical record their diagnosis of ADHD given by the specialist child and adolescent psychiatrist or the neurologist.

The following exclusion criteria were used: children whose parents/guardians did not sign the informed consent form and did not answer the anamnesis and questionnaires; children that did not complete all the assessments; children whose pure-tone threshold audiometry, conducted in the previous 12 months, had abnormal results; children whose clinical data included a diagnosis of severe conditions, namely: cognitive changes (such as intellectual disability), neuromotor changes (such as neuromotor dysfunction), or other psychiatric changes (such as schizophrenia, bipolar disorder, mood and anxiety disorders, and substance dependence). Based on these, the eligible population included 40 children, two of whom did not complete 
the assessment. Hence, the final sample comprised 38 children -27 boys and 11 girls.

The sociodemographic aspects were assessed with analysis of medical records and anamnesis of the parents/guardians. The Brazilian Economic Classification Criteria (CCEB, in Portuguese) ${ }^{16}$ was also used, as well as the Home Environment Resources Scale (RAF, in Portuguese) ${ }^{17}$, which assesses the resources that promote proximal processes, foreseeable activities that indicate some degree of family life stability, and parental practices that improve the family-school connection.

Besides the anamnesis, the children's parents/ guardians answered the Strengths and Difficulties Questionnaire $(\mathrm{SDQ})^{18}$ (whose objective is to detect mental health problems in children and youth) and the Pediatric Quality of Life Inventory ${ }^{\mathrm{TM}}$ (PedsQL), version $4.0^{19}$ (which assesses the parents'/guardians' perception of the child's quality of life). The positive symptoms of ADHD were characterized with the MTA-SNAP-IV ${ }^{15}$, an instrument that assesses the symptoms of ADHD and oppositional defiant disorder. This scale was developed based on the symptoms in the Diagnostic and Statistical Manual of Mental Disorders (DSM-IV), of the American Psychiatric Association. It must be pointed out that this instrument is not intended to diagnose the said disorders, but rather to survey some symptoms present in them.

The language comprehension, rapid automatic naming, and phonological working memory were respectively assessed with the Token $\mathrm{Test}^{20}$, the Rapid Automatic Naming test ${ }^{21}$, and the Phonological Working Memory test ${ }^{22}$.

The expressive and receptive vocabulary, writing, phonological awareness, and syntactic awareness were respectively assessed with the Child Language Test - phonology, vocabulary, fluency, and pragmatics (ABFW), of which the vocabulary part was used ${ }^{23}$; USP Picture Vocabulary Test (UPVT) - short form ${ }^{24}$; word and pseudoword dictation ${ }^{25}$, with material gathered from lists, distributed by frequency pattern, regularity, irregularity, and Brazilian Portuguese word norms (Pinheiro, 1994 and 2001); Phonological Awareness Test ${ }^{26}$; and Syntactic Awareness Test ${ }^{27}$. Their reading was assessed with the Reading Processes Assessment Tests (PROLEC) ${ }^{28}$ - full form.
In the first stage of data analysis, the clinical diagnosis of ADHD was confirmed by studying the medical records and the score surveyed with the MTA-SNAP-IV, to carry out the positive ADHD symptomatology. This study considered, besides the symptoms of inattention alone or hyperactivity alone, situations in which items related to both inattention and hyperactivity/impulsivity had been checked, following the criterion of at least six items checked for inattention and hyperactivity/impulsivity.

The collected data were electronically stored, being twice entered and later verified to eliminate errors. Descriptive analysis was conducted for the frequency distribution of categorical variables, and analysis of the measures of central tendency and dispersion of continuous variables.

Descriptive analyses were conducted for all the variables of the study, with the distribution of absolute and relative frequency of categorical variables and numerical synthesis of continuous variables. This study considered the classification of ADHD into three categories as the response variable, based on the symptomatology described in SNAP-IV. The explanatory variables were the oral language comprehension, oral language test performance, reading and writing test performance, RAF score, quality of life score, sociodemographic factors (age, sex, and CCEB economic classification), strengths and difficulties (SDQ), and pro-social behavior. The association analyses considered the response variable and the explanatory variables, kept in the original form for the bivariate analyses. Pearson's chi-square test was used for the association analysis of the categorical variables. As for the continuous variables with symmetrical distribution, the ANOVA (analysis of variance) was used, whereas the Kruskal-Wallis non-parametric test was used for the continuous variables with asymmetrical distribution.

The 5\% significance level and 95\% confidence interval were used in all the analyses. The quantitative data were entered, processed, and analyzed with the Statistical Package for the Social Sciences (SPSS), version 21.0.

\section{RESULTS}

The participants' sociodemographic and environmental data are described in Table 1. 
Table 1. Bivariate analysis of the association between the profiles of attention-deficit/hyperactivity disorder, according to the SNAP-IV scale and sociodemographic and environmental variables

\begin{tabular}{|c|c|c|c|c|c|}
\hline \multirow{2}{*}{ Characteristics } & \multicolumn{4}{|c|}{ SNAP-IV Classification } & \multirow{2}{*}{ p-value } \\
\hline & Inattentive & Hyperactive & Combined & Total & \\
\hline \multicolumn{6}{|l|}{ Sex } \\
\hline Females & $6(42.9)$ & $1(25.0)$ & $2(13.3)$ & $9(27.3)$ & \multirow{3}{*}{$0.202^{*}$} \\
\hline Males & $8(57.1)$ & $3(75.0)$ & $13(86.7)$ & $24(72.7)$ & \\
\hline Total & $14(100.0)$ & $4(100.0)$ & $15(100.0)$ & $33(100.0)$ & \\
\hline \multicolumn{6}{|l|}{$\begin{array}{l}\text { Child's age } \\
\text { (n) }\end{array}$} \\
\hline Mean & 9.9 & 10.0 & 9.07 & 8.6 & \multirow{2}{*}{$0.319^{* *}$} \\
\hline Standard Deviation & 1.70 & 1.20 & 1.6 & 1.1 & \\
\hline \multicolumn{6}{|l|}{ CCEB } \\
\hline Class A1 & $1(7.1)$ & $0(0.0)$ & $0(0.0)$ & $1(3.0)$ & \multirow{6}{*}{$0.503^{*}$} \\
\hline Class B1 & $4(28.6)$ & $0(0.0)$ & $2(13.3)$ & $6(18.2)$ & \\
\hline Class B2 & $4(28.6)$ & $3(75.0)$ & $4(26.7)$ & $11(33.3)$ & \\
\hline Class C1 & $3(21.4)$ & $1(25.0)$ & $5(33.3)$ & $9(27.3)$ & \\
\hline Class C2 & $2(14.3)$ & $0(0.0)$ & $4(26.7)$ & $6(18.2)$ & \\
\hline Total & $14(100.0)$ & $4(100.0)$ & $15(100.0)$ & $33(100.0)$ & \\
\hline \multicolumn{6}{|l|}{ RAF (total score) } \\
\hline Median & 57.0 & 54.6 & 51.6 & - & \multirow{3}{*}{0.537 ** } \\
\hline Mean & 54.5 & 55.2 & 50.3 & - & \\
\hline Standard Deviation & 11.5 & 6.0 & 11.4 & - & \\
\hline
\end{tabular}

Captions: CCEB = Brazilian Economic Classification Criteria; RAF = Home Environment Resources Scale *Pearson's chi-square; **ANOVA

Table 1 shows that none of the sociodemographic and environmental data was associated with the ADHD profiles.
The results of the association between variables of the Token Test, rapid automatic naming test, phonological working memory test, and ADHD profiles are shown in Table 2. 
Table 2. Bivariate analysis of the association between the profiles of attention-deficit/hyperactivity disorder, according to the SNAP-IV scale and the results of the Rapid Automatic Naming, Token, and Phonological Working Memory tests

\begin{tabular}{|c|c|c|c|c|c|}
\hline \multirow{2}{*}{ Characteristics* } & \multicolumn{4}{|c|}{ SNAP-IV Classification } & \multirow{2}{*}{$\mathrm{p}$-value } \\
\hline & Inattentive & Hyperactive & Combined & Total & \\
\hline \multicolumn{6}{|l|}{ Color Naming } \\
\hline Adequate & $10(71.4)$ & $4(100.0)$ & $9(60.0)$ & $23(69.7)$ & \multirow{3}{*}{$0.297^{\star *}$} \\
\hline Inadequate & $4(28.6)$ & $0(0.0)$ & $6(40.0)$ & $10(30.3)$ & \\
\hline Total & $14(100.0)$ & $4(100.0)$ & $15(100.0)$ & $33(100.0)$ & \\
\hline \multicolumn{6}{|l|}{ Letter Naming } \\
\hline Adequate & $9(64.3)$ & $3(75.0)$ & $7(50.0)$ & 19 (59.4) & \multirow{3}{*}{$0.590^{* *}$} \\
\hline Inadequate & $5(35.7)$ & $1(25.0)$ & $7(50.0)$ & $13(40.6)$ & \\
\hline Total & $14(100.0)$ & $4(100.0)$ & $14(100.0)$ & $32(100.0)$ & \\
\hline \multicolumn{6}{|l|}{ Object Naming } \\
\hline Adequate & $12(85.7)$ & $4(100.0)$ & $12(80.0)$ & $28(84.8)$ & \multirow{3}{*}{$0.608^{* *}$} \\
\hline Inadequate & $2(14.3)$ & $0(0.0)$ & $3(20.0)$ & $5(15.2)$ & \\
\hline Total & $14(100.0)$ & $4(100.0)$ & $15(100.0)$ & $33(100.0)$ & \\
\hline \multicolumn{6}{|l|}{ Token Final Classification } \\
\hline Mean 7 years & $0(0.0)$ & $0(0.0)$ & $3(20.0)$ & $3(10.3)$ & \multirow{7}{*}{$0.220^{* *}$} \\
\hline Mean 8 years & $3(21.4)$ & $1(25.0)$ & $1(9.1)$ & $5(17.2)$ & \\
\hline Mean 9 years & $1(7.1)$ & $1(25.0)$ & $0(0.0)$ & $2(6.9)$ & \\
\hline Mean 10 years & $1(7.1)$ & $1(25.0)$ & $1(9.1)$ & $3(10.3)$ & \\
\hline Mean under 7 years & $6(42.9)$ & $1(25.0)$ & $6(54.5)$ & $13(44.8)$ & \\
\hline Mean under 10 years & $3(21.4)$ & $0(0.0)$ & $0(0.0)$ & $3(10.3)$ & \\
\hline Total & $14(100.0)$ & $4(100.0)$ & $11(100.0)$ & $29(100.0)$ & \\
\hline \multicolumn{6}{|l|}{$\begin{array}{l}\text { Total Nonword Phonological } \\
\text { Working Memory }\end{array}$} \\
\hline 4 years 1 st quartile & $1(7.1)$ & $0(0.0)$ & $1(6.7)$ & $2(6.1)$ & \multirow{6}{*}{$0.246^{\star *}$} \\
\hline 5 years 1 st quartile & $1(7.1)$ & $0(0.0)$ & $4(26.7)$ & $5(15.2)$ & \\
\hline 6 years 1st quartile & $4(28.6)$ & $2(50.0)$ & $1(6.7)$ & $7(21.2)$ & \\
\hline 7 years 1st quartile & $1(7.1)$ & $1(25.0)$ & $0(0.0)$ & $2(6.1)$ & \\
\hline $\begin{array}{l}\text { Values above 1st quartile } 8 \\
\text { years }\end{array}$ & $7(50.0)$ & $1(25.0)$ & $9(60.0)$ & 17 (51.5) & \\
\hline Total & $14(100.0)$ & $4(100.0)$ & $15(100.00)$ & $33(100.0)$ & \\
\hline \multicolumn{6}{|l|}{$\begin{array}{l}\text { Total Digit Phonological } \\
\text { Working Memory }\end{array}$} \\
\hline 4 years 1 st quartile & $0(0.0)$ & $0(0.0)$ & $1(6.7)$ & $1(3.0)$ & \multirow{7}{*}{$0.188^{*}$} \\
\hline 5 years 1st quartile & $0(0.0)$ & $0(0.0)$ & $3(20.0)$ & $3(9.1)$ & \\
\hline 6 years 1 st quartile & $2(14.3)$ & $0(0.0)$ & $3(20.0)$ & $5(15.2)$ & \\
\hline 7 years 1 st quartile & $4(28.6)$ & $0(0.0)$ & $2(13.3)$ & $6(18.2)$ & \\
\hline 8 years 1 st quartile & $0(0.0)$ & $0(0.0)$ & $2(13.3)$ & $2(6.1)$ & \\
\hline $\begin{array}{l}\text { Values above 1st quartile } 8 \\
\text { years }\end{array}$ & $8(57.1)$ & $4(100.0)$ & $4(26.7)$ & $16(48.5)$ & \\
\hline Total & $14(100.0)$ & $4(100.0)$ & $15(100.00)$ & $33(100.0)$ & \\
\hline
\end{tabular}

*The amount of information varies due to missing data; **Pearson's chi-square 
No association between the results of these tests and the ADHD profiles ( $p$-value $>0,05$ ) was found.

The results of the expressive and receptive vocabulary, dictation, phonological awareness, and syntactic awareness tests, as well as their association with ADHD profiles, are presented in Table 3.

Table 3. Bivariate analysis of the association between the profiles of attention-deficit/hyperactivity disorder, according to the SNAP-IV scale and results of the Expressive and Receptive Vocabulary, Dictation, Phonological Awareness, and Syntactic Awareness tests

\begin{tabular}{|c|c|c|c|c|c|}
\hline \multirow{2}{*}{ Characteristics* } & \multicolumn{4}{|c|}{ SNAP-IV Classification } & \multirow{2}{*}{$\mathrm{p}$-value } \\
\hline & Inattentive & Hyperactive & Combined & Total & \\
\hline \multicolumn{6}{|c|}{ Expressive Vocabulary } \\
\hline Normal & $14(100.0)$ & $4(100.0)$ & $12(80.00)$ & $30(90.9)$ & \multirow{3}{*}{$0.138^{* *}$} \\
\hline Changed & $0(0.0)$ & $0(0.0)$ & $3(20.0)$ & $3(9.1)$ & \\
\hline Total & $14(100.0)$ & $4(100.0)$ & $15(100.0)$ & $33(100.0)$ & \\
\hline \multicolumn{6}{|c|}{ Receptive Vocabulary } \\
\hline Very Low & $5(35.7)$ & $1(25.0)$ & $5(33.3)$ & $7(28.0)$ & \multirow{5}{*}{$0.549 * *$} \\
\hline Low & $2(14.3)$ & $0(0.0)$ & $5(33.3)$ & $13(52.0)$ & \\
\hline Medium & $6(42.9)$ & $3(75.0)$ & $5(33.3)$ & $5(20.0)$ & \\
\hline High & $1(7.1)$ & $0(0.0)$ & $0(0.0)$ & $1(3.0)$ & \\
\hline Total & $12(100.0)$ & $4(100.0)$ & $9(100.0)$ & $33(100.0)$ & \\
\hline \multicolumn{6}{|c|}{$\begin{array}{l}\text { Total Errors in the Dictation of } \\
\text { High-Frequency Words }\end{array}$} \\
\hline Median & 4.0 & 3.5 & 3.0 & - & \multirow{3}{*}{$0.907^{* * *}$} \\
\hline Mean & 4.1 & 3.5 & 4.0 & - & \\
\hline Standard Deviation & 2.1 & 2.4 & 2.3 & - & \\
\hline \multicolumn{6}{|c|}{$\begin{array}{l}\text { Total Errors in the Dictation of } \\
\text { Low-Frequency Words }\end{array}$} \\
\hline Median & 6.0 & 4.0 & 6.0 & - & \multirow{3}{*}{$0.618^{\star \star *}$} \\
\hline Mean & 5.2 & 4.3 & 5.3 & - & \\
\hline Standard Deviation & 2.2 & 1.30 & 1.5 & - & \\
\hline \multicolumn{6}{|c|}{$\begin{array}{l}\text { Total Errors in the Dictation of } \\
\text { Pseudowords }\end{array}$} \\
\hline Median & 3.0 & 3.5 & 4.0 & - & \multirow{3}{*}{$0.574^{* * *}$} \\
\hline Mean & 4.2 & 3.3 & 4.7 & - & \\
\hline Standard Deviation & 3.3 & 1.0 & 1.9 & - & \\
\hline \multicolumn{6}{|c|}{ Phonological Awareness } \\
\hline Adequate & $1(7.1)$ & $1(25.0)$ & $0(0.0)$ & $2(6.1)$ & \multirow{3}{*}{$0.172^{\star *}$} \\
\hline Inadequate & $13(92.9)$ & $3(75.0)$ & $15(100.0)$ & $31(93.9)$ & \\
\hline Total & $14(100.0)$ & $4(100.0)$ & $15(100.0)$ & $33(100.0)$ & \\
\hline \multicolumn{6}{|c|}{ Syntactic Awareness } \\
\hline Very Low & $0(0.0)$ & $0(0.0)$ & $4(26.7)$ & $4(12.1)$ & \multirow{5}{*}{$0.143^{* *}$} \\
\hline Low & $0(0.0)$ & $0(0.0)$ & $1(6.7)$ & $1(3.0)$ & \\
\hline Mean & $8(57.1)$ & $1(25.0)$ & $7(46.7)$ & $16(48.5)$ & \\
\hline High & $6(42.9)$ & $3(75.0)$ & $3(20.0)$ & $12(36.4)$ & \\
\hline Total & $14(100.0)$ & $4(100.0)$ & $15(100.0)$ & $33(100.0)$ & \\
\hline
\end{tabular}

*The amount of information varies due to missing data; **Pearson's chi-square; ***Kruskal-Wallis 
No statistically significant associations were observed ( $p>0.05)$.
The results of the association analyses between SNAP and PROLEC results are given in Table 4.

Table 4. Bivariate analysis of the association between the profiles of attention-deficit/hyperactivity disorder, according to the SNAP-IV scale and results of the Reading Processes Assessment Tests

\begin{tabular}{|c|c|c|c|c|c|}
\hline \multirow{2}{*}{ Characteristics* } & \multicolumn{4}{|c|}{ SNAP-IV Classification } & \multirow{2}{*}{$\mathrm{p}$-value } \\
\hline & Inattentive & Hyperactive & Combined & Total & \\
\hline \multicolumn{6}{|c|}{ Letter Name or Sounds } \\
\hline Normal & $7(50.0)$ & $3(75.0)$ & $5(33.3)$ & $15(45.5)$ & \multirow{4}{*}{$0.459 *$} \\
\hline Difficulty & $5(35.7)$ & $1(25.0)$ & $5(33.3)$ & $11(33.3)$ & \\
\hline Great difficulty & $2(14.3)$ & $0(0.0)$ & $5(33.3)$ & $7(21.2)$ & \\
\hline Total & $14(100.0)$ & $4(100.0)$ & $15(100.0)$ & $33(100.0)$ & \\
\hline \multicolumn{6}{|l|}{ Equal-Different } \\
\hline Normal & $4(33.3)$ & $1(25.0)$ & $2(22.2)$ & $7(28.0)$ & \multirow{4}{*}{$0.717^{* x}$} \\
\hline Difficulty & $7(58.3)$ & $2(50.0)$ & $4(44.4)$ & $13(52.0)$ & \\
\hline Great difficulty & $1(8.3)$ & $1(25.0)$ & $3(33.3)$ & $5(20.0)$ & \\
\hline Total & $12(100.0)$ & $4(100.0)$ & $9(100.0)$ & $25(100.0)$ & \\
\hline \multicolumn{6}{|l|}{ Lexical Decision } \\
\hline Normal & $8(66.7)$ & $3(75.0)$ & $5(55.6)$ & $16(64.0)$ & \multirow{4}{*}{$0.880^{*>}$} \\
\hline Difficulty & $2(16.7)$ & $1(25.0)$ & $2(22.2)$ & $5(20.0)$ & \\
\hline Great difficulty & $2(16.7)$ & $0(0.0)$ & $2(22.2)$ & $4(16.0)$ & \\
\hline Total & $12(100.0)$ & $4(100.0)$ & $9(100.0)$ & $25(100.0)$ & \\
\hline \multicolumn{6}{|l|}{ Word reading } \\
\hline Normal & $6(50.0)$ & $4(100.0)$ & $3(33.3)$ & $13(52.0)$ & \multirow{4}{*}{$0.291^{* x}$} \\
\hline Difficulty & $3(25.0)$ & $0(0.0)$ & $3(33.3)$ & $6(24.0)$ & \\
\hline Great difficulty & $3(25.0)$ & $0(0.0)$ & $3(33.3)$ & $6(24.0)$ & \\
\hline Total & $12(100.0)$ & $4(100.0)$ & $9(100.0)$ & $25(100.0)$ & \\
\hline \multicolumn{6}{|c|}{ Pseudoword Reading } \\
\hline Normal & $6(50.0)$ & $4(100.0)$ & $1(11.1)$ & $11(44.0)$ & \multirow{4}{*}{$0.055^{\star \star}$} \\
\hline Difficulty & $1(8.3)$ & $0(0.0)$ & $1(11.1)$ & $2(8.0)$ & \\
\hline Great difficulty & $5(41.7)$ & $0(0.0)$ & $7(77.8)$ & $12(48.0)$ & \\
\hline Total & $12(100.0)$ & $4(100.0)$ & $9(100.0)$ & $25(100.0)$ & \\
\hline \multicolumn{6}{|c|}{$\begin{array}{l}\text { Word and Pseudoword Reading: } \\
\text { frequent words }\end{array}$} \\
\hline Normal & $7(58.3)$ & $3(75.0)$ & 3 (33.3) & $13(52.0)$ & \multirow{4}{*}{$0.559 * *$} \\
\hline Difficulty & $2(16.7)$ & $1(25.0)$ & $3(33.3)$ & $6(24.0)$ & \\
\hline Great difficulty & $3(25.0)$ & $0(0.0)$ & $3(33.3)$ & $6(24.0)$ & \\
\hline Total & $12(100.0)$ & $4(100.0)$ & $9(100.0)$ & $25(100.0)$ & \\
\hline \multicolumn{6}{|c|}{$\begin{array}{l}\text { Word and Pseudoword Reading: } \\
\text { infrequent words }\end{array}$} \\
\hline Normal & $6(50.0)$ & $2(50.0)$ & $3(33.3)$ & $11(44.0)$ & \multirow{4}{*}{$0.900^{* x}$} \\
\hline Difficulty & $3(25.0)$ & $1(25.0)$ & 2 (22.2) & $6(24.0)$ & \\
\hline Great difficulty & $3(25.0)$ & $1(25.0)$ & $4(44.4)$ & $8(32.0)$ & \\
\hline Total & $12(100.0)$ & $4(100.0)$ & $9(100.0)$ & $25(100.0)$ & \\
\hline
\end{tabular}




\begin{tabular}{|c|c|c|c|c|c|}
\hline \multirow{2}{*}{ Characteristics* } & \multicolumn{4}{|c|}{ SNAP-IV Classification } & \multirow{2}{*}{ p-value } \\
\hline & Inattentive & Hyperactive & Combined & Total & \\
\hline \multicolumn{6}{|c|}{$\begin{array}{l}\text { Word and Pseudoword Reading: } \\
\text { pseudowords }\end{array}$} \\
\hline Normal & $5(41.7)$ & $2(50.0)$ & 2 (22.2) & $9(36.0)$ & \multirow{4}{*}{$0.675^{* *}$} \\
\hline Difficulty & $2(16.7)$ & $1(25.0)$ & $1(11.1)$ & $4(16.0)$ & \\
\hline Great difficulty & $5(41.7)$ & $1(25.0)$ & $6(66.7)$ & $12(48.0)$ & \\
\hline Total & $12(100.0)$ & $4(100.0)$ & $9(100.0)$ & $25(100.0)$ & \\
\hline \multicolumn{6}{|c|}{ Grammatical Structures } \\
\hline Normal & $8(72.7)$ & $4(100.0)$ & $9(100.0)$ & $21(87.5)$ & \multirow{4}{*}{$0.132^{* *}$} \\
\hline Difficulty & $3(27.3)$ & $0(0.0)$ & $0(0.0)$ & $3(12.5)$ & \\
\hline Great difficulty & $0(0.0)$ & $0(0.0)$ & $0(0.0)$ & $0(0.0)$ & \\
\hline Total & $11(100.0)$ & $4(100.0)$ & $9(100.0)$ & $24(100.0)$ & \\
\hline \multicolumn{6}{|c|}{ Punctuation Marks } \\
\hline Normal & $9(81.8)$ & $4(100.0)$ & $7(77.8)$ & $20(83.3)$ & \multirow{4}{*}{$0.907^{* *}$} \\
\hline Difficulty & $1(9.1)$ & $0(0.0)$ & $1(11.1)$ & $2(8.3)$ & \\
\hline Great difficulty & $1(9.1)$ & $0(0.0)$ & $1(11.1)$ & $2(8.3)$ & \\
\hline Total & $11(100.0)$ & $4(100.0)$ & $9(100.0)$ & $24(100.0)$ & \\
\hline \multicolumn{6}{|c|}{ Clause Comprehension } \\
\hline Normal & $5(45.5)$ & $2(50.0)$ & $5(55.6)$ & $12(50.0)$ & \multirow{4}{*}{$0.751^{* *}$} \\
\hline Difficulty & $3(27.3)$ & $2(50.0)$ & $2(22.1)$ & $7(29.2)$ & \\
\hline Great difficulty & $3(27.3)$ & $0(0.0)$ & $2(22.1)$ & $5(20.8)$ & \\
\hline Total & $11(100.0)$ & $4(100.0)$ & $9(100.0)$ & $24(100.0)$ & \\
\hline \multicolumn{6}{|c|}{ Text Comprehension } \\
\hline Normal & $3(27.3)$ & $2(50.0)$ & $1(11.1)$ & $6(25.0)$ & \multirow{4}{*}{$0.368 * *$} \\
\hline Difficulty & $3(27.3)$ & $2(50.0)$ & $3(33.3)$ & $8(33.3)$ & \\
\hline Great difficulty & $5(45.5)$ & $0(0.0)$ & $5(55.6)$ & $10(41.7)$ & \\
\hline Total & $11(100.0)$ & $4(100.0)$ & $9(100.0)$ & $24(100.0)$ & \\
\hline
\end{tabular}

*The amount of information varies due to missing data; **Pearson's chi-square

There was no association between the variables and the ADHD profiles ( $p>0.05)$. However, "pseudoword reading" had a borderline association ( $p=0.055)$, with a greater proportion of "great difficulty" answers in the combined profile.
The association analysis data between the ADHD profiles, the PedsQL domain scores, its overall result, and the SDQ total impact score are shown in Table 5. 
Table 5. Bivariate analysis of the association between the profiles of attention-deficit/hyperactivity disorder, according to the SNAP-IV scale, the Pediatric Quality of Life Inventory ${ }^{\mathrm{TM}}$ (PedsQL), and the results of the Strengths and Difficulties Questionnaire (SDQ)

\begin{tabular}{|c|c|c|c|c|c|}
\hline \multirow{2}{*}{ Characteristics } & \multicolumn{4}{|c|}{ SNAP-IV Classification } & \multirow{2}{*}{ p-value } \\
\hline & Inattentive & Hyperactive & Combined & Total & \\
\hline \multicolumn{6}{|l|}{ PedsQL } \\
\hline Median & 76.5 & 77.5 & 62.0 & - & \multirow{3}{*}{$0.108^{*}$} \\
\hline Mean & 70.9 & 77.3 & 58.7 & - & \\
\hline Standard Deviation & 19.1 & 11.6 & 19.6 & - & \\
\hline \multicolumn{6}{|l|}{$\begin{array}{l}\text { Total Score of the } \\
\text { Difficulties }\end{array}$} \\
\hline Normal & $2(14.3)$ & $0(0.0)$ & $0(0.0)$ & $2(6.1)$ & \multirow{4}{*}{$0.092^{* x}$} \\
\hline Borderline & $3(21.4)$ & $0(0.0)$ & $0(0.0)$ & $3(9.1)$ & \\
\hline Abnormal & $9(64.3)$ & $4(100.0)$ & $15(100.0)$ & $28(84.8)$ & \\
\hline Total & $14(100.0)$ & $4(100.0)$ & $15(100.0)$ & $33(100.0)$ & \\
\hline \multicolumn{6}{|c|}{ Total Score of the Impact } \\
\hline Normal & $0(0.0)$ & $2(50.0)$ & $2(13.3)$ & $4(12.1)$ & \multirow{4}{*}{$0.003^{\star x}$} \\
\hline Borderline & $3(21.4)$ & $2(50.0)$ & $0(0.0)$ & $5(20.0)$ & \\
\hline Abnormal & $11(78.6)$ & $0(0.0)$ & 13 (86.7) & $24(72.7)$ & \\
\hline Total & $14(100.0)$ & $4(100.0)$ & $15(100.0)$ & $33(100.0)$ & \\
\hline
\end{tabular}

*Kruskal-Wallis; **Pearson's chi-square

There was no significant association between the PedsQL variables. Regarding SDQ, the total impact score had a statistically significant association with the ADHD profiles. There was a greater proportion of abnormal results in the inattentive and combined profiles $(p=0.003)$.

\section{DISCUSSION}

The investigation of inattention and hyperactivity symptoms, language development, and cognitive, environmental, socioeconomic, and quality of life aspects in children with ADHD indicated a statistically significant association between the ADHD profiles and the SDQ total score. Hence, the analysis encompasses the scores related to the child's global suffering and social difficulties. The significant association between this domain and the ADHD profiles may reflect the reality experienced by the children and their families, insofar as the psychosocial health is impaired and consequently so is the family's and child's quality of life. Factors such as the family's stress level, especially when there are comorbidities, affective and social difficulties, negative parental practices, and lack of family support need to be considered in the disorder ${ }^{29}$. The main national studies using the SDQ assessed children with school difficulties ${ }^{30}$ and typical reading development ${ }^{31}$; they also searched the prevalence of mental health problems in primary healthcare of 6- to 11-year-old children ${ }^{32}$ and analyzed the association between family context variables and the risk of emotional/behavioral problems in children ${ }^{33}$. Another study that stands out is a longitudinal one with 1,176 Danish children, whose objective was to predict mental disorders in preadolescence. It demonstrated that, rather than used alone, the SDQ should be an integral part of a screening battery to follow up behavioral development ${ }^{34}$.

In the present study, there was no statistically significant association between the sociodemographic and environmental data and the ADHD profiles. Concerning the family environment, a national study with 6- to 13-year-old children and adolescents with ADHD revealed that family functioning is strongly associated with the disorder. A greater prevalence of ADHD was verified in the homes with some family dysfunction when compared with families with better relationships ${ }^{14}$. On the other hand, in the same study, socioeconomic conditions such as low income and the number of people in the household were not associated with ADHD.

The children's performance in the Rapid Automatic Naming, Phonological Working Memory - Digits and Words, Token, expressive vocabulary, receptive vocabulary, dictation, phonological awareness, and syntactic awareness tests had no association with the 
ADHD profiles in this study. Nevertheless, the clinical importance of some results must be considered. In the Rapid Automatic Naming test, a worse performance was verified in letter naming, followed by color, digit, and object naming (Table 2). Rapid naming, which is one of the phonological processing skills, is related to reading in terms of decoding, fluency, and comprehension skills $8,12,35$. The skills necessary to rapid naming include attention, perceivably changed in cases of ADHD. Likewise, in the pseudoword reading task, the performance of children with ADHD in the combined profile was worse than those in the other profiles in the rapid automatic naming test, restating the changes in the attentional processes, memory, and phonological processing in the sample studied.

Concerning the Token Test, the inattentive and combined profiles had similar performances (Table 2). This datum confirms that inattention, which is impaired in both profiles, has an essential role in language comprehension and gives clues to investigate cognition more in-depth.

In the Phonological Working Memory test, there were more children in the inattentive and combined profiles, whose performance corresponded to the expected in younger children. These data agree with the hypothesis of differentiating the profiles, in relation to the neuropsychological profiles presented by the ADHD patients. The problems related to selective attention and information processing speed are associated with the predominantly inattentive profile, with worse performances in visuomotor dexterity, processing speed, and verbal mnemonic retrieval tests. The difficulties paying attention for longer periods are associated with the predominantly hyperactive profile, with a performance similar to that of normal subjects in these tests ${ }^{10}$.

There was a worse performance in the receptive than in the expressive vocabulary test (Table 3). The result of children with ADHD in the combined profile was similar to that of children with the inattentive profile. These data and those of the Token Test may be explained by the working memory organization mode ${ }^{36}$, whose main components are a central executive and two subsystems, namely: the phonological loop (related to verbal material representation, storage, and handling) and the visuospatial subsystem (related to the objects' visual and spatial properties). The phonological loop functions with phonological codes but its storage is limited because of the quick deterioration of verbal material through time. To minimize this aspect, two other phonological loop subsystems work complementarily - one related to the phonological storage (phonological loop) and the other related to the subvocal or articulatory loop.

The visuospatial loop or subsystem retains information, as well as the phonological loop, only that it is visuospatial in this case. There are two complementary components in this subsystem also - one maintains visual material and the other handles spatial material. Hence, the visuospatial subsystem is responsible for processing and storing visuospatial material. It must be highlighted that the child must handle both verbal and visual information concomitantly when performing the receptive vocabulary test and the Token Test.

Concerning the written test with dictation, misspellings predominated in low-frequency words, while the misspellings had the same average in writing pseudowords and high-frequency words (Table 3). These data contradict what is expected from the effect of the level of familiarity with words. It is expected that, the higher the frequency with which a word occurs, the higher the precision when writing it and the involvement of the lexical process, both in reading aloud and writing ${ }^{30}$. Thus, the errors in relation to the levels of familiarity were expected to occur more often with pseudowords, then low-frequency words, and less often with high-frequency words.

In the present study, the similar average of errors in pseudowords and high-frequency words in the three ADHD profiles indicates a need for investigating the underlying processes in the writing of schoolchildren with ADHD, as well as the exclusion of comorbidities. In children with a specific reading disorder, the predominance of errors in low-frequency words may be related to difficulties either learning the lexical representation of new words or performing the orthographic processing ${ }^{31}$.

As for the performance in the metalinguistic skills, the inattentive and combined profiles had similar results in the phonological awareness assessment (Table 3) - the phonological awareness skills were inadequate in both profiles. These data point to the relationship between the difficulties presented by the children assessed in this study regarding reading and writing skills. The phonological awareness, the access to the mental lexicon, and the phonological working memory are integral parts of phonological processing - which is characterized by mental operations based on the oral language structure ${ }^{12}$. In this regard, phonological awareness skills in the inattentive and combined profiles could be influenced, among 
other things, by the attentional processes. Some of the studies that assessed the performance of children with and without ADHD in phonological awareness skills revealed a worse performance in the first group than in the second ${ }^{8,11}$. A Brazilian study ${ }^{37}$ conducted with 9- to 12-year-old children showed that schoolchildren with ADHD had a worse performance in phonological awareness skills, access to the lexicon, working memory, and word reading and writing than their peers without ADHD and good school achievement.

The performance in the syntactic awareness test was similar to that of the abovementioned tests - alike between the inattentive and combined profiles and a predominance of errors in the combined profile. The literature ${ }^{38}$ shows that children with changes in syntactic awareness have written narrative deficits. Hence, it is essential to better investigate the consequences of such changes in children and adolescents with ADHD.

Regarding the reading processes, the pseudoword reading task had a borderline association (Table 4), with a greater proportion of answers related to greater difficulty in children with ADHD in the combined profile (Table 4). The reading process involves word recognition, which may occur through either the lexical or phonological route. The first one is related to the direct visual process, while the second one is related to phonological mediation. Thus, the phonological route is related to the reading of pseudowords, while the lexical route is related to the reading of regular words ${ }^{7}$. The use of both the lexical and phonological routes is expected to improve as one grows up and advances in school. ${ }^{8}$. The data revealed in this study suggest an impairment in the use of the phonological route in children with $A D H D$, corroborating their worse performance in the reading processes 7,12 . The worse performance of the combined profile in relation to the other profiles may be due to hyperactivity, inattention, and impulsivity, which are characteristic of the condition.

Concerning the quality of life and profiles in ADHD, despite the absence of statistically significant associations in this study, the literature reveals the existence of difficulties with impact on the quality of life of children and adolescents with $\mathrm{ADHD}^{4,13}$. In this context, the sample size - which is also the main limitation of this study - may explain the absence of association.

Although in comparison with epidemiologic studies few children were assessed, a large number of tests and assessments were carried out, with an in-depth analysis of the associations of the clinical profiles (hyperactive, inattentive, and combined) with the speech-language-hearing and socio-environmental aspects. However, the combined profile must be cautiously analyzed, as only four subjects represented it.

The present research was based on the clinical and socio-environmental perspectives of children diagnosed with ADHD. Therefore, it contributes to discuss and guide its diagnosis and the speechlanguage-hearing intervention. Also, the complex diagnosis of and approach to ADHD ${ }^{39}$ point to the need for more robust studies with this population - either longitudinal studies or randomized clinical trials - and more in-depth study of the associations between the SDQ subscales and the speech-language-hearing tests in this population.

\section{CONCLUSION}

This study enabled the assessment of various aspects related to the development of children with ADHD referred to the Speech-Language-Hearing Service of the Hospital at the institution of origin. No statistically significant associations were found between the predominance of ADHD symptoms and most of the variables analyzed in this study. However, the better performance of children with hyperactive profiles, as well as the similar performance between the combined and predominantly inattentive profiles, suggest that the attentional mechanisms are the main intervening factor.

\section{REFERENCES}

1. APA: American Psychiatric Association. Diagnostic and Statistical Manual of Mental disorders DSM-5. 5th ed. Washington: American Psychiatric Association; 2013.

2. Varma A, Wiener J. Perceptions of ADHD symptoms in adolescents with attention-deficit/hyperactivity disorder: attributions and stigma. Canadian Journal of School Psychology [journal on the Internet]. 2020 Sep [cited 2020 Sep 28]; [about 7 p.]. Available at: https://doi.org/10.1177/0829573520936459

3. Root A, Brown JP, Forbes HJ, Bhaskaran K, Hayes $\mathrm{J}$, Smeeth $\mathrm{L}$ et al. Association of relative age in the school year with diagnosis of intellectual disability, attention-deficit/hyperactivity disorder, and depression. JAMA Pediatr. 2019;173(11):1068-75. 
4. Segenreich D, Fortes D, Coutinho G, Pastura G, Mattos $P$. Anxiety and depression in parents of a Brazilian non-clinical sample of attention-deficit/ hyperactivity disorder (ADHD) students. Braz J Med Biol Res. 2009;42(5):465-9.

5. Limbers CA, Ripperger-Suhler J, Heffer RW, Varni JW. Patient-reported Pediatric Quality of Life

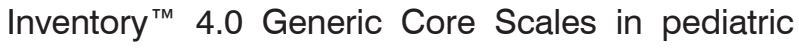
patients with attention-deficit/hyperactivity disorder and comorbid psychiatric disorders: feasibility, reliability, and validity. Value Health. 2011;14(4):521-30.

6. Xu G, Strathearn L, Liu B, Yang B, Bao W. Twenty-year trends in diagnosed Attention-Deficit/ Hyperactivity Disorder among US children and adolescents, 1997-2016. JAMA Netw Open. 2018;1(4):e181471.

7. Oliveira AM, Cardoso MH, Padula NAMR, Lourencetti MD, dos Santos LCA, Capellini SA. Reading processes in students with Attention Deficit Hyperactivity Disorder. Psicol Argum. 2013;31(72):35-44.

8. Cunha VLO, da Silva C, Lourencetti MD, Padula NAMR, Capellini SA. Performance of students with attention deficit disorder and hyperactivity in metalinguistic and reading tasks. Rev. CEFAC. 2013;15(1):40-50.

9. Capellini SA, Ferreira TL, Salgado CA, Ciasca SM. Performance of good readers, students with dyslexia and attention deficit hyperactivity disorder in rapid automatized naming. Rev Soc Bras Fonoaudiol. 2007;12(2):114-9.

10. Messina LF, Tiedemann KB. Assessment of working memory in children with attention deficit hyperactivity disorder. Psicol USP. 2009;20(2):209-28.

11. Oliveira AM, Cardoso MH, Pinheiro FH, Germano GD, Capellini SA. Performance of students with dyslexia and attention deficit disorder with hyperactivity in the reading assessment processes. Rev Bras Crescimento Desenvolv Hum. 2011;21(2):344-55.

12. Klein Al, Lamprecht RR. A compreensão em leitura e a consciência fonológica em crianças com Transtorno de Déficit de Atenção e Hiperatividade. Signo. 2012;37(63):25-54.
13. Cappe E, Bolduc M, Rougé MC, Saiag MC, Delorme R. Quality of life, psychological characteristics, and adjustment in parents of children with AttentionDeficit/Hyperactivity Disorder. Qual Life Res. 2017;26(5):1283-94.

14. Pires TO, da Silva CMFP, de Assis SG. Family environment and attention-deficit hyperactivity disorder. Rev Saúde Pública. 2012;46(4):624-33.

15. Mattos P, Serra-Pinheiro MA, Rohde LA, Pinto D. A Brazilian version of the MTA-SNAP-IV for evaluation of symptoms of attention-deficit/hyperactivity disorder and oppositional-defiant disorder. Rev Psiquiatr. 2006;28(3):290-7.

16. Abep.org/criterio-brasil. [homepage na Internet]. São Paulo: Associação Brasileira de Empresas de Pesquisa (ABEP) [updated on 11 Mar 2021; accessed on 21 Mar 2021]. Available at: http:// www.abep.org/criterio-brasil.

17. Marturano EM. The home environment resources scale. Psicol Reflex Crit. 2006;19(3):498-506.

18. Goodman R. The Strengths and Difficulties Questionnaire: a research note. J Child Psychol Psychiatry. 1997;38(5):581-6.

19. Varni JW, Seid M, Kurtin PS. PedsQL 4.0: reliability and validity of the Pediatric Quality of Life Inventory TM Version 4.0 generic core scales in healthy and patient populations. Med Care. 2001;39(8):800-12.

20. Malloy-Diniz LF, Bentes RC, Figueiredo PM, Brandão-Bretas D, da Costa-Abrantes S, Parizzi AM et al. Standardisation of a battery of tests to evaluate language comprehension, verbal fluency and naming skills in Brazilian children between 7 and 10 years of age: preliminary findings. Rev. Neurol. 2007;44(5):275-80.

21. Denckla MB, Rudel R. Rapid "automatized" naming of pictured objects, colors, letters and numbers by normal children. Cortex. 1974;10(2):186-202.

22. Hage SRV, Grivol MA. Reference values of nonword repetition test for Brazilian Portuguese-speaking children. J Appl Oral Sci. 2009;17(spe):63-8.

23. Andrade CRF, Befi-Lopes DM, Fernandes FDM, Wertzner HF. ABFW: Teste de Linguagem Infantil Nas Áreas de Fonologia, Vocabulário, Fluência e Pragmática. São Paulo: Pró-Fono; 2004.

24. Capovilla FC. Teste de Vocabulário Por Figuras USP - TVfusp: Normatizado para avaliar compreensão auditiva de palavras dos 7 aos 10 anos. São Paulo: Memnon; 2011. 
25. Pinheiro AMV, Rothe-Neves R. Cognitive Assessment of Reading and Writing: ReadingAloud and Spelling Tasks. Psicol Reflex Crit. 2001;14(2):399-408.

26. Santos MTM, Pereira LD. Teste de Consciência Fonológica. In: Pereira LD, Schochat E, editors. Processamento Auditivo Central: manual de avaliação. São Paulo: Lovise; 1997. p. 187-95.

27. Capovilla FC, Capovilla AGS. Prova de Consciência Sintática (PCS): normatizada e validada para avaliar a habilidade metassintática de escolares de 1a a 4 a séries do ensino fundamental. São Paulo: Memnon; 2006.

28. Capellini SA, Oliveira AM, Cuetos F. PROLEC: Provas de Avaliação dos Processos de Leitura. São Paulo: Pearson; 2010.

29. Rezende FP, Calais SL, Cardoso HF. Stress, parenting and family support in attention deficit/ shyperactivity disorder. Psicol Teor Prat. 2019;21(2):153-71.

30. D'Abreu LCF, Marturano EM. Identificação de problemas de saúde mental associados à queixa escolar segundo o DAWBA. Psico. 2011;42(2):152-8.

31. Stivanin L, Scheuer $\mathrm{Cl}$, Assumpção Júnior $\mathrm{F}$. SDQ (Strengths and Difficulties Questionnaire): identification of children readers behavioral characteristics. Psic Teor e Pesq. 2008,24(4):407-13.

32. Fatori D, Brentani A, Grisi SJFE, Miguel EC, Graeff-Martins AS. Childhood mental health problems in Primary Care. Ciênc Saúde Coletiva. 2018;23(9):3013-20.

33. Ferriolli SHT, Marturano EM, Puntel LP. Family context and child mental health problems in the Family Health Program. Rev Saúde Pública. 2007;41(2):251-9.

34. Nielsen LG, Rimvall MK, Clemmensen L, Munkholm A, Elberling $\mathrm{H}$, Olsen EM et al. The predictive validity of the Strengths and Difficulties Questionnaire in preschool age to identify mental disorders in preadolescence. PloS One. 2019;14(6):e0217707.

35. Alves DC, Casella EB, Ferraro AA. Spelling performance of students with developmental dyslexia and with developmental dyslexia associated to attention deficit disorder and hyperactivity. CoDAS. 2016;28(2):123-31.

36. Baddeley AD, Hitch GJ, Allen RJ. From short-term store to multicomponent working memory: The role of the modal model. Mem Cogn. 2019;47:575-88.
37. Gonçalves-Guedim TF, Capelatto IV, SalgadoAzoni CA, Ciasca SM, Crenitte PAP. Performance of children with attention deficit hyperactivity disorder in phonological processing, reading and writing. Rev. CEFAC. 2017;19(2):242-52.

38. Soares ACC, Zuanetti PA, da Silva K, GuedesGranzotti RB, Fukuda MTH. Written narrative of students with and without difficulty in syntactic awareness. J Hum Growth Dev. 2020;30(3):372-9.

39. Randell R, Somerville-Brown L, Chen W. How relevant is higher-order language deficit (HOLD) to children with complex presentations of attentiondeficit hyperactivity disorder? Atten Defic Hyperact Disord. 2019;11(3):325-32. 